\title{
BMJ Open UK parents' attitudes towards meningococcal group B (MenB) vaccination: a qualitative analysis
}

\author{
Cath Jackson, ${ }^{1}$ Joanne Yarwood, ${ }^{2}$ Vanessa Saliba, ${ }^{2}$ Helen Bedford ${ }^{3}$
}

To cite: Jackson C, Yarwood J, Saliba V, et al. UK parents' attitudes towards meningococcal group $\mathrm{B}$ (MenB) vaccination: a qualitative analysis. BMJ Open 2017;7:e012851. doi:10.1136/ bmjopen-2016-012851

- Prepublication history and additional material for this paper are available online. To view these files please visit the journal online (http://dx.doi.org/ 10.1136/ bmjopen-2016-012851)

Received 29 May 2016 Revised 21 March 2017 Accepted 21 March 2017

CrossMark

${ }^{1}$ Department of Health Sciences, University of York, York, UK

${ }^{2}$ Public Health England, London, UK

${ }^{3} \mathrm{UCL}$ Great Ormond Street Institute of Child Health, London, UK

Correspondence to

Dr. Helen Bedford;

h.bedford@ucl.ac.uk

\section{ABSTRACT}

Objectives (1) To explore existing knowledge of, and attitudes, to group B meningococcal disease and serogroup $B$ meningococcal (MenB) vaccine among parents of young children. (2) To seek views on their information needs.

Design Cross-sectional qualitative study using individual and group interviews conducted in February and March 2015, prior to the introduction of MenB vaccine (Bexsero) into the UK childhood immunisation schedule.

Setting Community centres, mother and toddler groups, parents' homes and workplaces in London and Yorkshire. Participants 60 parents of children under 2 years of age recruited via mother and baby groups and via an advert posted to a midwife-led Facebook group.

Results Although recognising the severity of meningitis and septicaemia, parents' knowledge of group B meningococcal disease and MenB vaccine was poor. While nervous about fever, most said they would take their child for MenB vaccination despite its link to fever. Most parents had liquid paracetamol at home. Many were willing to administer it after MenB vaccination as a preventive measure, although some had concerns. There were mixed views on the acceptability of four vaccinations at the 12-month booster visit; some preferred one visit, while others favoured spreading the vaccines over two visits. Parents were clear on the information they required before attending the immunisation appointment.

Conclusions The successful implementation of the MenB vaccination programme depends on its acceptance by parents. In view of parents' recognition of the severity of meningitis and septicaemia, and successful introduction of other vaccines to prevent bacterial meningitis and septicaemia, the MenB vaccination programme is likely to be successful. However, the need for additional injections, the likelihood of post-immunisation fever and its management are issues about which parents will need information and reassurance from healthcare professionals. Public Health England has developed written information for parents, informed by these findings.

\section{INTRODUCTION}

Following the successful introduction of meningococcal C (MenC) vaccine in 1999, ${ }^{1}$ serogroup B is the leading cause of meningococcal disease in the UK accounting for $85 \%-90 \%$ of all cases and with the highest incidence in infants. ${ }^{2}$ In September 2015,
Strengths and limitations of this study

This is the only current UK study providing detailed, up-to-date information for Public Health England and primary care health professionals to facilitate the successful implementation of serogroup B meningococcal vaccine.

- A mix of parents across parental age, ethnicity and number of children were recruited; these parental characteristics are associated with uptake of childhood vaccination.

- Parents with a university degree or fully immunised children were over-represented in the study.

the UK introduced routine meningococcal $B$ vaccination (MenB) into the childhood immunisation schedule at 2, 4 and 12 months of age. ${ }^{3}$

The successful implementation of vaccines depends on many factors including parental acceptability. Since meningitis is recognised by parents to be a serious, potentially life-threatening infection ${ }^{4}$ and the perceived severity of an infection is an important determinant of vaccine acceptance, ${ }^{5}$ the prospects for a successful MenB programme are good. However, the introduction of MenB vaccine raises specific issues, which may impact on its acceptability for some parents and which need addressing to ensure successful implementation.

First, although MenB is well evaluated in trials and in campaigns, ${ }^{67}$ the UK is the first country to introduce Bexsero (a specific MenB vaccine) as a publicly funded programme to help prevent group B meningococcal disease. Second, more injections are needed: a total of three at the 2-month and 4-month vaccination visits and four at the 12-month visit. Endorsement by healthcare professionals plays an important role in parental acceptance of multiple injections ${ }^{89}$; however, an increasing number of vaccines and multiple injections offered routinely concerns some parents who feel, although misguidedly, that 
too many vaccines may overwhelm their child's immune system. ${ }^{4}$ Parents also worry about increased pain and possible adverse events following multiple injections. ${ }^{9}$ In the USA, where more vaccines and vaccine doses are recommended, some parents are reported to delay or even decline vaccines. ${ }^{10}$ In view of some existing parental concern about the number of vaccines already recommended, there is the potential for this to be mirrored in the UK.

Third, when MenB vaccine is administered to infants concomitantly with other vaccines, it gives rise to higher levels $(51 \%-61 \%)$ of fever $\left(\geq 38^{\circ} \mathrm{C}\right)$ compared with routine vaccines given alone $(23 \%) .^{7}$ To reduce this risk, the Joint Committee on Vaccination and Immunisation recommended that when MenB vaccine is given with the other vaccines at 2 and 4 months of age, parents should be advised to administer paracetamol prophylactically. ${ }^{3}$ This represents a change in advice on managing fever, based on the National Institute for Health and Care Excellence guidance, that antipyretics should not be given in anticipation of a fever and only if a child appears distressed. ${ }^{11}$ Since fever is also a concern for parents, ${ }^{12}{ }^{13}$ they will be required to consider the balance of risks between the threat of meningitis and the likelihood of fever following the vaccine.

We aimed to explore parents' knowledge of, and attitudes to, MenB disease and MenB vaccine. We also sought views on their information needs, which included commenting on the content of communications developed by Public Health England (PHE). These comments are not presented here as they were fed back directly to PHE.

\section{METHODS}

\section{Study design}

This was a cross-sectional qualitative study.

\section{Participants and recruitment}

A large body of literature, ${ }^{14-19}$ identifies two broad categories of parental factors influencing uptake of childhood vaccination. The first relates to socioeconomic disadvantage where, despite being motivated to have their children vaccinated, parents lack access to resources and support to overcome logistical barriers such as no private transport (access). The second relates to parents' concerns about the safety or beliefs about the necessity of vaccines (acceptance). To ensure that we spoke with parents in both categories, we set out to recruit 60 parents of children under the age of 2 years across different parental age, socioeconomic status (using education as a proxy), ethnicity and number of children.

Parents were recruited in London and Yorkshire. In London, parents were recruited in five Children's Centres (CC) from two London districts, which were selected for their sociodemographic mix. Written permission was secured to conduct the study in these CCs. HB attended mother and baby sessions in the CCs and distributed study information to parents, returning a week later to conduct interviews with consenting parents. In Yorkshire, parents were recruited from two mother and toddler groups (after securing permission from group leaders) by distributing study information and via an advert posted to a midwife-led Facebook group. Interested mothers contacted CJ for more information and interviews were conducted subsequently. We did not formally record how many parents were approached and then agreed/ declined to be interviewed.

\section{Data collection}

Individual and group interviews were conducted by $\mathrm{CJ}$ and HB in February and March 2015 prior to the announcement of the introduction of MenB vaccine. Both have considerable experience as immunisation researchers; and HB was previously a health visitor. They presented themselves to participants as independent to the MenB vaccination programme and advised that any specific questions about immunisation would be answered after the interviews. The written study information reassured parents that they could end/leave the interview at any point without offering a reason why. Parents who individually contacted the research team to participate were interviewed on their own in their home or workplace. Parents recruited through the CCs and mother and toddler groups took part in group interviews conducted away from the main mother and baby session. The topic guide (see online supplementary file 1) was piloted with four parents of children under the age of 2 years. No changes were made. Interviews explored:

- Awareness of MenB disease and vaccine

- Perceptions of fever

- Attitudes to use of paracetamol as a prophylactic for fever

- Attitudes to an increased number of injections at each vaccination visit

- Preferences for the number of injections at each vaccination visit

- The most important information needed in the MenB leaflets

In the group interviews, the researcher asked participants in turn to respond to the interview questions. Individual interviews lasted between 28 and $57 \mathrm{~min}$. Group interviews lasted between 30 and $65 \mathrm{~min}$. All interviews were digitally audio-recorded.

\section{Data analysis}

The audio-recordings were transcribed verbatim and personal data anonymised. The individual and group interview data were analysed together using the six steps of thematic analysis. This is a method of 'identifying, analysing and reporting patterns (themes) within the data': p4. ${ }^{20}$ It is a useful approach for producing qualitative analyses suited to informing programme development. The six steps were as follows:

- Familiarisation: both researchers (CJ and HB) became immersed in the raw data by 'repeated 
reading' of the transcripts and listed key ideas for coding.

- Generating initial codes: initial codes and a coding framework were developed by CJ, informed predominantly by the study objectives (a deductive approach), although novel views expressed by participants were also captured (an inductive approach). The interview data were then coded by CJ to this framework using NVivo V.10 software.

- Searching for themes: the codes were then organised by $\mathrm{CJ}$ into potential themes and subthemes. At this point, similarities and differences in views across education, ethnicity and number of children were explored.

- Reviewing themes: the coded data within each potential theme were reviewed by CJ and $\mathrm{HB}$ and the themes modified to ensure that they formed a coherent pattern. Each theme was then reviewed to see if it 'worked' in relation to the entire data set.

- Defining and naming themes: a short paragraph was produced by $\mathrm{CJ}$ for each theme and subthemes to define the 'essence' of the theme/subthemes and names were allocated.

- Producing the report: the thematic analysis was written up by CJ.

\section{Ethics approval}

University College London Research Ethics Committee approved the study and parents gave written informed consent to take part.

\section{FINDINGS}

\section{Participants}

Information was gathered from 60 parents (table 1) through 7 individual and 12 group interviews (range 2-7 parents). While the sample size was prespecified, data saturation occurred in that no new relevant knowledge emerged in the final few interviews. Two-thirds (62\%) lived in London and one-third $(38 \%)$ were from Yorkshire. Participants were predominantly female $(92 \%)$ and two-thirds $(65 \%)$ were first time parents. Their age range was 20-43 years. Half were white British (55\%). Half $(55 \%)$ were educated to Bachelor degree or higher. Two parents were medically trained. Participants' children $(\mathrm{n}=62)$ ranged from 12 days to 24 months of age. Almost all participants (92\%) self-reported that their child/children were fully immunised.

\section{Parents' views}

We have reported findings based on thematic analysis of the data. Where views differ according to parents' characteristics, these are indicated. Illustrative quotes are presented throughout.

\section{Views on MenB disease and vaccination}

Knowledge about MenB and perception of risk of the disease

Although most parents were unfamiliar with the term 'meningococcal disease', they had heard of meningitis, recognising it to be life threatening and needing urgent medical attention. They identified high temperature, fever and a rash (recognised using the glass test) as symptoms to look out for (quote 1, table 2). Parents were generally unsure of details of how meningococcal infection spreads, its incidence and who is most likely to catch it (quote 2, table 2). A minority of parents mentioned different strains (commonly $\mathrm{C}$ ), but they were less aware of how strains differ, although it was suggested the difference was viral-bacterial or due to severity. Parents were generally less knowledgeable about septicaemia but knew it to be serious. Four parents who were well informed about both forms of meningococcal disease were either medically trained or had paid privately for their children to have the MenB vaccination.

\begin{tabular}{|c|c|c|c|}
\hline & & $\mathbf{N}$ & $\%$ \\
\hline \multirow[t]{2}{*}{ Site } & London & 37 & 62 \\
\hline & Yorkshire & 23 & 38 \\
\hline \multirow[t]{2}{*}{ Gender } & Male & 5 & 8 \\
\hline & Female & 55 & 92 \\
\hline \multirow[t]{7}{*}{ Ethnicity } & White British & 33 & 55 \\
\hline & White other & 10 & 16 \\
\hline & $\begin{array}{l}\text { Black British } \\
\text { Caribbean }\end{array}$ & 4 & 7 \\
\hline & Black African & 5 & 8 \\
\hline & Asian Chinese & 1 & 2 \\
\hline & Asian other & 4 & 7 \\
\hline & Missing & 3 & 5 \\
\hline \multirow{4}{*}{$\begin{array}{l}\text { Highest } \\
\text { educational } \\
\text { qualification }\end{array}$} & $\begin{array}{l}\text { GCSE or } \\
\text { equivalent }\end{array}$ & 6 & 10 \\
\hline & $\begin{array}{l}\text { A level or } \\
\text { equivalent }\end{array}$ & 15 & 25 \\
\hline & $\begin{array}{l}\text { Bachelor } \\
\text { degree or } \\
\text { higher }\end{array}$ & 33 & 55 \\
\hline & Missing & 6 & 10 \\
\hline \multirow{3}{*}{$\begin{array}{l}\text { No. of } \\
\text { children }\end{array}$} & One & 39 & 65 \\
\hline & $\begin{array}{l}\text { More than } \\
\text { one }\end{array}$ & 20 & 33 \\
\hline & Missing & 1 & 2 \\
\hline \multirow{4}{*}{$\begin{array}{l}\text { Self-reported } \\
\text { Immunisation } \\
\text { Status of } \\
\text { children }\end{array}$} & Full & 55 & 92 \\
\hline & Partial & 3 & 5 \\
\hline & None & 1 & 2 \\
\hline & Missing & 1 & 2 \\
\hline & & Mean (SD) & Range \\
\hline \multicolumn{2}{|c|}{ Mean age of parent (years) } & $31.6(5.10)$ & $20-43$ \\
\hline \multicolumn{2}{|c|}{$\begin{array}{l}\text { Mean age of children under } \\
2 \text { years (months) }\end{array}$} & $8.7(5.60)$ & $\begin{array}{l}12 \text { days to } \\
24 \text { months }\end{array}$ \\
\hline
\end{tabular}

GCSE, General Certificate of Secondary Education. 
Table 2 Illustrative quotes - knowledge of, and attitudes to, MenB disease and vaccination

1 Q. So what do you know about meningitis?

I know that it can cause fatality, it's very important to be identified quickly, and get the child medical help as, as soon as possible; and you usually associate it with the rash, like you know the clear glass you put on the, on the rash, it doesn't go away.

Y004a (White British father, fully immunised children, individual interview)

2 How it can come on, it can progress, that, I mean I wouldn't know that, so, and I wouldn't know the symptoms of it either.... or if they did have it, you know, I wouldn't know what would be worrying or what; I mean, you know, kids get fevers and they get, you know, ear infections, chest infections, things like that, but I wouldn't know what would mean it's this, how would you know it's definitely this? Y008a (White British mother, fully immunised children, individual interview)

3 It's gonna need more information, I think, because it's a new vaccine, everyone's gonna be wary of it, it's not an old vaccine that's been around for years already, and I think for a new vaccine they're gonna need to put more information than that on it, personally, because obviously everyone's gonna be wary of it. L007g (Asian British mother, non-immunised children, group interview)

4 Q: So you hadn't heard of it in your role as a GP?

No. No, I hadn't heard of it, and, and it does tend to be at the point of implementation that we, we tend to hear...cos there's so much, so much going on I suppose all the time.

Y009a (White British mother, fully immunised children, individual interview)

\section{Knowledge of and attitudes to MenB vaccine}

Some parents knew that there were vaccines in the schedule to protect against meningococcal disease, they most commonly mentioned MenC. Most had not heard of MenB vaccine. Because of this parents did not initially identify any safety concerns associated with MenB vaccine, although a small minority talked about feeling nervous when a new vaccine is introduced and their concerns that it has been sufficiently tested (quote 3 , table 2). The four parents who were well informed about MenB disease were also knowledgeable about MenB vaccine, although a GP had not yet heard about it in her professional role (quote 4 , table 2).

Views on the increased risk of fever following vaccination

\section{Managing fever}

Most parents expressed worry about fever, particularly its cause and how it might progress, for example, febrile convulsions (quote 1, table 3 ). They described a variety of strategies to manage fever: removing clothing, applying a damp cloth/putting the child in the bath, checking the child's temperature and administering liquid paracetamol (identified as Calpol). While many parents discussed using Calpol, a small number acknowledged that it cannot be used extensively with very young babies (quote 2, table 3). Some recognised that their confidence in managing fever had developed as their child got older as they 'could gauge' the child better (quote 3, table 3).

\section{Concerns about fever}

Most parents described becoming concerned about fever based on their child's temperature and if it persists (quote 4 , table 3). At this point, they would seek advice from their GP or Health Visitor, telephone 111 or if very concerned go to Accident and Emergency. First-time mothers were more likely to report seeking help immediately, often from a knowledgeable family member.

\section{Fever caused by vaccination}

Some parents said that they would be less worried knowing a fever is caused by vaccination in that, to some extent, it is expected (quote 5 , table 3 ) with a few commenting that fever is preferable to meningitis (quote 6, table 3).

Other parents expressed concern that a vaccine would elicit fever. Several of these, most of whom were first-time parents, talked about this being particularly worrying when their child is aged 2 months. This was because it is their first appointment for vaccinations, they do not know their baby well yet and cannot administer much Calpol to a child so young (quote 7 , table 3 ).

\section{Would the fever deter parents from accepting MenB vaccine?}

The overwhelming majority of parents said that despite the link with fever, it would not prevent them having MenB vaccine. A few explained that this is because they trust that it has been tested and is safe (quote 8, table 3). A minority talked about making specific preparations such as considering the timing of the appointment (quote 9, table 3) or looking into this vaccination very carefully to be reassured it is worth having.

\section{Acceptability of administering paracetamol post-vaccination Routine administration of paracetamol}

Most parents said that they have Calpol at home and routinely use it, although not when a child is aged only 2 months (quote 1 , table 4). A small minority of parents described having difficulties giving their child Calpol as he/she spits it out. Two parents appeared to not know that Calpol is liquid infant paracetamol. A few parents (one GP) pointed out that the regular instructions for administering Calpol to a baby aged 2 months are different to the advice for use of paracetamol post-MenB vaccination; and that this inconsistency might worry and confuse parents (quote 2, table 4). Two parents did not agree with giving their child paracetamol because of concerns about its side effects and the view that it is used far more routinely 
Table 3 Illustrative quotes-views on fever

1 Yeah, it's, it's scary. Two weeks ago she had a fever, she had it at about, almost 40 her fever was, and it, it is really scary, cos she would literally get really hot to where her face goes red, she's all sweating, then she'll cool down and get really, really hot again, and it's really hard to manage cos you don't know what to do, cos you don't know whether you should be putting cold, cold towel on them like, but you don't wanna shock their body into like all this cold, coldness at once, cos that's where they start, they start fitting. She had a, a small little fit, like a small convulsion, cos she got too hot.

L007g (Asian British mother, non-immunised children, group interview)

2 See that's, the only, the only problem that you have with that is that when they're eight weeks old, no, four weeks old, anything under the, under the age of three months you have to be careful how much Calpol and stuff you can give them, and the only thing you can give them is Calpol. So they are really careful, they, they do tell you to be really careful, but. So if they get a really bad fever, you can only give them one dose of Calpol in a 24 hours period, and that's the 2.5. I mean that should work, but if it didn't you're a bit stuck as a parent as to what you can do to help baby settle down.

Y006a (White British mother, fully immunised children, group interview)

3 I feel that now she's nine months I'm, I'm more confident when she gets sick or has, has had a fever now, I understand her more and I have natural instincts of how to look after her and how bad she is I can gauge, where when she was younger and she did get a fever from some, the, I think it was the two months, the sixteen week one, I'm not sure, that I was so scared when she was, fell ill and, you know, the, the only kind of conversation you get is, if they should get a temperature give them Calpol, but you're just so stressed as it is when they're so young that to have it so, to have it so young is just, to gauge the fever that young is more scary than when they are older, yeah.

L008d (British Philippines mother, fully immunised children, group interview)

4 It (NHS Choices) tells you if a temperature lasts more than three, seventy two hours that you should be worried. I know from my personal experience when (name of daughter) had a temperature and I have, and it's not been breaking for more than about forty-eight hours, that's when I've started to worry.

L005a (White British mother, fully immunised children, individual interview)

5 And, and what I find reassuring with the imm, immunisation induced fevers you sort of know what it is, whereas if it's just a random, you know, incident, you'd never, I don't know, I'd be more worried if I, if it was non-immunisation related.

L001a (White British mother, fully immunised children, group interview)

6 It's better than meningitis.

Y007a (White British mother, fully immunised children, group interview)

I'd rather him have a fever...

Y007b (White British mother, fully immunised children, group interview)

That's what I mean, you can, you can control fever with Calpol and certain things. If they get baby ill from not having the vaccine, it's a lot harder to control than a fever.

Y007a

7 I, I wouldn't be happy with it. Cos at 2 months you've not given her paracetamol before and you don't know what the side effects are. If she had a fever I would give it to her. But no, I wouldn't like the idea of, personally, at so young.

L004a (White British mother, fully immunised children, group interview)

8 Q. Would you have it for your baby if the MenB vaccine was introduced?

I'd be so worried about a brand new vaccine, like our generation being kind of tested on it almost, but I think if it was the fact that everyone did and it's, I probably would, I'd be worried about it though, but I would, if it was, yeah.

L003c (Black British African mother, fully immunised children, group interview)

Q. Because it's a new thing?

Yeah, it's a new thing and they've been tested, you know, but I think, I think I would.

L003c

Yeah, again I probably would, I mean it, I would probably, the increased risk of fever would be worrying, but I think if there's anything that they can be protected against, I tend to just go along with what the government are recommending, and if they, if they say it's safe and I tend to just believe that that's, that's true (laughs) trust that it's true, and, and go with it, and I think l'd rather have them immunised against something and have a little bit of a fever for a day than not, and just them, them catching something awful. (laughs)

L003g (White British mother, fully immunised children, group interview)

I'd still have to be so convinced that it was worth it for, to have fever and for them to be having extra stuff in their bodies... I'd need to be really convinced it was worthwhile.

L003a (Polish mother, partially immunised children, group interview)

9 Q. Does that (the fever) change how you feel about taking him?

It doesn't, for me not necessarily, no, cos I suppose at least if you know it's gonna happen you can be equipped with the tools to deal with it, and you can be practical in terms of when you go and have that done and being ready for it and working around it.

Y005a (White British mother, fully immunised children, individual interview) 
Table 4 Illustrative quotes-acceptability of administering paracetamol post-vaccination

1 Q. Has everybody got paracetamol at home?

About two months I didn't, but now he's getting a bit older I have got some in, in, just in case, cos of teething and vaccinations and everything else. But at, at, at two months probably not.

L007e (White British mother, fully immunised children, group interview)

2 People will worry about, cos it says, the, the advice on the bottle is from three months and then there's just like a one-off post-immunisation dose in younger ones. So you'd have to be quite clear that it was safe; I think parents will worry about the safety of giving more than, more paracetamol than is prescribed on the bottle you're buying.

Y009a (White British mother, fully immunised children, individual interview)

3 I have allergic just when you're saying paracetamol. I'm not agreeing with paracetamol. I know a whole country they been treating with paracetamol but I don't accept this.

$\mathrm{Q}:$ But in terms of fever and how to deal with it?

It, but you under, just look, they treat you with everything, all sickness they give you paracetamol, it's can't be, can't be helpful this stuff. But if you understand me, I don't, I'm not gonna use paracetamol.

L002a (Polish mother, fully immunised children, group interview)

4 I suppose if I knew it was gonna stop him being unwell I'd do it. So I suppose if they're saying there's a higher risk that he's gonna be unwell straight after it, give him Calpol to try and make him comfortable I wouldn't have a concern with that. But yeah, I mean I don't think as a mum you'd want your child to be in any pain so if someone tells you take this and it's not gonna hurt you'd do it wouldn't you?

Y005a (White British mother, fully immunised children, individual interview)

5 What if the paracetamol actually doesn't lower the fever then at what point do I say, you know, cos if I go to the doctors and say, oh, you know, he's had the vaccinations but he's got a fever, and they tend to say, oh yeah, it's absolutely fine, it's due to the vaccinations, but then at what point do I say, OK, well he has had the vaccinations but the fever's carried on going up, paracetamol's not working, given him Ibuprofen, what now?

L008c (Black British African mother, fully immunised children, group interview)

6 I think if it was me as well I would have issues about the appropriateness of just giving (name of daughter) paracetamol for the sake of giving her paracetamol when she's not got a temperature. So I could understand, I think I would feel happier giving her a dose of paracetamol for, for a temperature rather than a dose of paracetamol just for the sake of having paracetamol. I don't think I would probably give (name of daughter) the paracetamol, if she was asleep I wouldn't wake her up.

L005a (White British mother, fully immunised children, individual interview)

in the UK compared with their home country (quote 3, table 4).

\section{Administration of paracetamol as a preventive measure}

Views on parents' willingness to administer prophylactic paracetamol after MenB vaccination differed. Many parents would be willing to administer paracetamol on the assumption that this is best for their child, even if they were worried about doing so (quote 4, table 4). However, questions were raised about whether they should wake a sleeping baby to administer a dose, or whether the third dose could be given the following morning, and what should they do if they forget to give the paracetamol or if the paracetamol does not work (quote 5, table 4).

However, a few parents expressed worries about administering prophylactic paracetamol. Reasons for this were a preference not to give paracetamol to their child generally, that their child struggles to take paracetamol (they spit it out), a worry about putting something else into the child's body after vaccination and that paracetamol might mask vaccine side effects. Several of these parents explicitly stated that they would not give their child the paracetamol after MenB vaccination unless the child develops a fever (quote 6, table 4).
Acceptability of four injections at the 12-month booster visit

Most parents were accepting of the vaccination schedule, trusting that it is informed by sound research and therefore safe (quote 1, table 5). A small number mentioned that the schedule is complex and busy, which can be particularly hard to 'keep a handle on' with a new baby. Views on the acceptability of four injections at the 12-month appointment differed.

Some parents (often with more than one child) preferred all four injections in one visit. This view was based on practical reasons such as the inconvenience of booking and finding time to attend multiple appointments, particularly for those mothers who have returned to work by 12 months (quote 2, table 5 ). They acknowledged that there would be an increased likelihood of them missing appointments if they are on different days. These parents also talked about preferring to 'get it all over with in one go' in terms of reducing distress to the child at the appointment and afterwards (quote 3, table 5). A few of these parents spoke about their child being more 'robust' by 12 months and so they felt more comfortable in taking them for multiple injections at that age.

Just over half of parents expressed a preference to separate the vaccines over different visits with most preferring two injections at two visits a month apart, although two 
Table 5 Illustrative quotes - acceptability of four vaccines at 12-month booster visit

1 I just put my trust in the fact that it's the best thing for her and I'm sure the healthcare professionals know what they are doing and so I don't think about it too much.

L004b (White British mother, fully immunised children, group interview)

2 I just, with having two really young children, the logistics of getting a doctor's appointment, getting there, and if, it sounds odd but if they're gonna be ill anyway, and as long as the fever's not more dangerous, I'm not too, I, I don't feel strongly. L001a (White British mother, fully immunised children, group interview)

3 I know it's not nice when they're having it done, but it only lasts for a few minutes, and I think for the sake of having the whole build up of going back again for another set and will they get another fever again and will it happen again, I think sometimes it's just... Best to get it all out of the way, let them have their five min' cry and forget it. (laughter) L003c (White British mother, fully immunised children, group interview)

4 I'll prefer to split because her immune system, you know, can be built and have a chance; if you give too much, you never know what could happen. OK, it's in one sense that's like, you know, we have to come back a few times, but on the other hand it's my baby, you know, health, so...

L003a (Polish mother, partially immunised children, group interview)

parents wanted even more visits with fewer injections at each. These preferences were predominantly to avoid fever (if that is associated with the MenB vaccine at this age) and distress to the baby on the day (quote 4, table 5). A small number of parents talked about preferring to avoid overloading their child's immune system with multiple vaccines. These issues were more important for these parents than the potential inconvenience of multiple appointments.

A few parents suggested that they should be given a choice about the 12-month booster visit as they know what works best for their child. Similar numbers of parents disagreed, preferring to be offered the safest approach as well as acknowledging the difficulty of implementing a choice system.

\section{Information needs \\ Information about MenB disease}

Parents wanted to understand why MenB disease is something they need to vaccinate their child against. To achieve this, they wanted to know how to recognise it, what are the signs and symptoms (identified as the most important information; quote 1, table 6) and how many people catch it. They were also interested in who is most at risk, how it spreads and how it is different to other strains of meningococcal disease.

\section{Information about MenB vaccine}

Parents identified the most important information to be about the vaccine's short-term and long-term side effects, likely occurrence and how to respond to them (quote 1, table 6). They also wanted information that compares the benefits versus the risks of the vaccine, facts on how it has been tested and if it has been used elsewhere. Other details of the vaccine that parents were interested in were: the reason it is needed in addition to MenC vaccine, why it does not protect against all meningococcal disease and how it is administered (number and timing of doses, injection/oral/nasal spray). They also wanted to understand why it causes fever, the likelihood of fever if administered alongside other vaccines and what would prevent their child having the injection on the day.

\section{Information about fever and paracetamol}

Parents identified the most important information about fever and paracetamol to be about how to administer paracetamol following MenB vaccination (dose, frequency, what happens if it does not work (quote 2, table 6). They also wanted to be informed of alternatives to giving paracetamol, and advised whether they should wake a sleeping baby to administer the paracetamol. Understanding what level and length of fever is normal, when should they be concerned and where should they go to seek help was also a priority.

\section{Timing of information}

Most parents preferred to have information about MenB vaccine and the associated fever before they attend the appointment (quote 3, table 6). Suggested methods of doing this were: sending the leaflet out with the invitation letter, giving it to the parent when they book the appointment at the GP practice or the practice nurse/health visitor providing it in routine appointments a few weeks before. A few parents said that while they would prefer to receive the MenB vaccine leaflet in advance, they would want the paracetamol leaflet at the appointment as that is the time they will focus on the specifics of timing and dosage (quote 4, table 6). Two parents talked about preferring to have information about all vaccinations before the baby is born as they had time and 'headspace' then to read it (quote 5, table 6).

\section{DISCUSSION}

This study explored parents' knowledge of and attitudes to MenB disease and of MenB vaccine, and parents' information needs to inform (a) the introduction of the MenB vaccine into the childhood schedule and (b) the information materials developed by PHE. To our knowledge, this is the only current UK study providing detailed, 
Table 6 Illustrative quotes-information needs

1 Well I like, obviously that, you know, this would make me, the statistics would make me think oh right, I need to get that done, the fear of the disease, you know, knowing what it is and what it can do would make, help me make the decision as well. And then, but then this one has all about the signs and symptoms and things like that, which, I mean you would want to know especially after the injection, more information about how to deal with the effects of the illness itself. Y008a (White British mother, fully immunised children, individual interview)

$2 Q$. What's the most important issue for you to know about the paracetamol and fever? What's the key thing the leaflet needs to include?

How much.

Y007e (White British father, fully immunised children, group interview)

How often.

Y007b (White British mother, fully immunised children, group interview)

...like a big space in sort of like, cos it only says here, I mean a lot of people might skim over that or misread it, for the dose Y007d (White British mother, fully immunised children, group interview)

Q. So the dose is the key thing you want guidance on?

Yeah.

Y007d

3 Q. When would you want to get this leaflet, when would it be most useful?

I guess maybe with the letter that you get to take, you know. Yeah, cos I wouldn't want it to arrive for the vaccination and be like, right, here's a leaflet do you want it now? l'd be like oh my gosh, I don't know, but maybe with a letter when you're due for your vaccination saying, you know, this is the new one, would you be happy to have it? At least then I can book then... Y008a (White British mother, fully immunised children, individual interview)

4 I would want this on the day at the time as you would if you were going for anything to your doctors, so that you can use it as a, a refer to for whatever treatment you've then got to follow when you get home.

Y005a (White British mother, fully immunised children, individual interview)

5 Um (pause) probably before they have the baby, I think, because when you've just had a baby and you're all over the place and your life is completely turned upside down and then you have to take your sleep deprived self and the baby at eight weeks to have their first vaccination, I think, you know, even if people don't read it, when they go to antenatal classes or the midwife gives them it, I think you're more likely when you're pregnant to have the time to do it, especially when it's your first baby, when you're more focused on just that.

L001a (White British mother, fully immunised children, group interview)

up-to-date information for PHE and primary care health professionals to facilitate the successful implementation of MenB vaccine.

Our aim was to capture the views of parents across the two broad categories of parental factors that influence uptake of childhood vaccination (socioeconomic disadvantage, concern about safety or necessity of vaccines) ${ }^{13-18}$ Although the proportion of parents in this study with a university degree $(55 \%)$ was higher than the proportion reported nationally for a comparable age group (about $40 \%),{ }^{20}$ diversity was achieved in other factors which are associated with uptake of childhood vaccination, namely ethnicity, parental age and number of children. We recruited in settings outside the National Health Service (NHS) increasing the likelihood of speaking to parents with a range of views. We have no reason to believe that the parents in this study from Yorkshire and London are markedly different to other parents in the UK; either in terms of their social contexts which impact on their access to immunisation services or their acceptance of immunisation. With the exception of one mother, the parents self-reported to be full or partial immunisers, reflecting the parents most likely to attend for MenB vaccination.

We investigated similarities and differences in views across parents of different education, ethnicity and number of children; and only identified a small number of differing views according to the number of children a parent had. As with all interview studies, there may have been some 'social desirability' in participants' accounts and responses could have been influenced by others in the group interviews. These group interviews were usually with mothers attending the same mother and baby group, or groups of friends and couples. They were typically lively discussions and we observed many frank exchanges of opinion with conflicting views emerging on several issues. This is reassuring. Moreover, the parents interviewed all had very young children, they had recent experience of the immunisation process and of making immunisation decisions. However, at the time of the study the introduction of MenB vaccine had not yet been announced and so parents' views about the vaccine, in particular, whether it would be acceptable were hypothetical.

Although most of the parents surveyed were not familiar with the term meningococcal disease, they recognised meningitis and septicaemia to be serious, life-threatening conditions. In their consideration of MenB, it was clear that for these parents, trusting the NHS and, by definition, healthcare professionals, is a key influence on their acceptance of vaccines. This is a finding that has been repeatedly reported elsewhere..$^{21}{ }^{22}$ This was evident in the view expressed by many parents that they will accept new vaccines or changes to the schedule because they trust the 
NHS to make evidence-based decisions and in particular, that vaccines have been appropriately tried and tested.

This also appeared to be the case for fever, if pre-warned that this is a likely consequence of MenB vaccine, most would not be deterred from accepting the vaccine. Advising parents of the likely adverse events following a vaccine is an important part of the immunisation process. Vaccine safety is a top priority for parents and if prepared for side effects with advice on their management, they are likely to be less concerned. This was borne out in one trial of the MenB vaccine, which included cohorts of parents who either knew or did not know which vaccines their child was receiving. Medical attention rates for fever were lower among parents who knew their child was receiving MenB vaccine, underlining the importance of advising parents about the possibility of fever following this vaccine. ${ }^{23}$

Based on parental reports of their experiences of the immunisation process, we identified elements where improvements are required. For example, some mothers reported feeling pressurised into accepting vaccines and first-time mothers in particular found the process stressful. Healthcare professionals may need reminding that the nature of their interactions is a key factor in influencing a parent's attitudes to immunisation ${ }^{24}$; this includes not assuming that attendance for immunisation indicates parents have no questions or concerns. Making this assumption or lacking empathy about parents' distress over the pain their child is experiencing may lead to future defaulting. ${ }^{25}$ This is particularly important with the introduction of MenB vaccine, when infants will be given three injections at their first immunisation visit at 8 weeks of age.

In contrast, it has also been reported that healthcare professionals may overestimate parents' concerns about their child receiving multiple injections. ${ }^{9}$ Although some parents in our study expressed concern about the pain, distress and possible impact on their child's immune system of having an additional injection, most felt this was outweighed by the value of protection against such a serious infection. The introduction of MenB will have led to some initial queries or concerns from both healthcare professionals and parents about the need for an additional injection, but experience from the introduction of other vaccines suggests that it quickly becomes acceptable practice. ${ }^{9}$ Again, this underlines the importance of a positive recommendation from a confident, well informed healthcare professional in securing parental acceptance of vaccines. ${ }^{9}$

MenB vaccine is another significant milestone in the prevention of bacterial meningitis and septicaemia. Our findings mirror those from other studies conducted in other high-income countries in Europe ${ }^{26-28}$ and Australia, ${ }^{29}$ although there were considerable differences in the populations sampled in terms of age and sampling methods. Only one other study explicitly explored the hypothetical impact on vaccine acceptance of an increased risk of mild-to-moderate fever associated with the vaccine. That study reported that it reduced intent to immunise for only a small proportion. ${ }^{29}$ The recommendation to give prophylactic paracetamol after the MenB doses at 2 and 4 months represents a change in advice with potential for confusion. Most parents in our study reported that despite some concerns, if advised to do so they would be likely to administer paracetamol. However, some may be reluctant and healthcare professionals need to be equipped to discuss this issue with parents. It will be important to monitor the side effects of MenB vaccine on a population level and whether increased rates of fever affect uptake of the vaccine or attendance rates in primary care and Accident and Emergency.

The successful implementation of the MenB vaccination programme requires: increased parental awareness of the infection, the safety and effectiveness of the vaccine, the likelihood of fever and its management if given concomitantly with other vaccines as well as the safety of giving multiple vaccines. Although we did not identify any new issues for parents in this study regarding vaccines, it was still important to explore their views and to consider their information needs. PHE developed written information for parents, which was informed by our findings. ${ }^{30-32}$ Resources to support the introduction of the vaccine were also developed for healthcare professionals. ${ }^{33}$

In view of the successful implementation of other vaccines to prevent meningitis and septicaemia (Haemophilus influenzae type $\mathrm{b}$, MenC, pneumococcal conjugate vaccine) ${ }^{34}$ and on the basis that parents' perceptions of the severity of a disease is an important determinant of vaccine uptake, ${ }^{19}$ the prospects for the successful introduction of MenB vaccine seem good. MenB vaccine was introduced into the routine vaccine schedule in the UK in September 2015 with three doses given at 2, 4 and 12 months concomitantly with other vaccines. ${ }^{35}$ Preliminary vaccine coverage data suggest this has successfully been integrated into the national programme with uptakes of $94.3 \%$ for one dose and $91.5 \%$ for two doses at 12 months of age. ${ }^{36}$ Our findings may be useful for other high-income countries when considering the implementation of a MenB vaccine programme in highlighting potential issues that need to be addressed. However, in view of differences between population groups in terms of attitudes to, and acceptability of, specific vaccines, it would be important to explore whether other issues may apply that could influence vaccine acceptance.

Acknowledgements The authors would like to thank the Children's Centres, mother and toddler groups and the midwife who facilitated recruitment to the study. The authors are also grateful to the parents who gave up their time to participate.

Contributors JY and VS conceived the study. All authors were responsible for the development and refinement of the study methods. CJ and HB conducted all data collection and data analysis. CJ and HB drafted the manuscript. All authors contributed to the revisions and approved the final manuscript. All authors agreed to be accountable for all aspects of the work.

Competing interests None declared.

Patient consent No personal medical information about an identifiable living individual is presented in the manuscript.

Ethics approval University College London Research Ethics Committee. 
Provenance and peer review Not commissioned; externally peer reviewed.

Data sharing statement There are no unpublished data available.

Data sharing statement This work was supported by PHE. The study funders were involved in the study conception, design, interpretation of data, writing of the article and decision to submit the article for publication. They did not contribute to data collection or data analysis. The research team operated completely independently of the funders in data collection and data analysis.

Open Access This is an Open Access article distributed in accordance with the Creative Commons Attribution Non Commercial (CC BY-NC 4.0) license, which permits others to distribute, remix, adapt, build upon this work non-commercially, and license their derivative works on different terms, provided the original work is properly cited and the use is non-commercial. See: http://creativecommons.org/ licenses/by-nc/4.0/

(c) Article author(s) (or their employer(s) unless otherwise stated in the text of the article) 2017. All rights reserved. No commercial use is permitted unless otherwise expressly granted.

\section{REFERENCES}

1. Borrow R, Abad R, Trotter C, et al. Effectiveness of meningococcal serogroup C vaccine programmes. Vaccine 2013;31:4477-86.

2. Ladhani SN, Flood JS, Ramsay ME, et al. Invasive meningococcal disease in England and Wales: implications for the introduction of new vaccines. Vaccine 2012;30:3710-6.

3. NHS England, Public Health England. Introduction of MenB immunisation for infants. London: NHS England, 2015. https://www. gov.uk/government/uploads/system/uploads/attachment_data/file/ 437906/150622_MenB bipartite_letter.pdf.

4. Bedford H, Lansley M. More vaccines for children? parents' views. Vaccine 2007;25:7818-23.

5. Peckham $\mathrm{C}$, Bedford $\mathrm{H}$, Senturia $\mathrm{Y}$, et al. National immunisation study: factors influencing immunisation uptake in childhood. Horsham: Action Research for the Crippled Children, 1989.

6. de Wals $P, 2015$. Results of a mass immunisation campaign with 4-components serogroup $b$ meningococcal vaccine (4CMenB) in Quebec, Canada. Oral Presentations at Meningitis Research Foundation Conference London. http://www.meningitis.org/conference2015\#Wals

7. Gossger N, Snape MD , L-m Y, et al. Immunogenicity and tolerability of recombinant serogroup $B$ meningococcal vaccine administered with or without routine infant vaccinations according to different immunization schedules: a randomized controlled trial. JAMA 2012;307:573-82.

8. World Health Organisation. Multiple injections: protecting infants as soon as possible. multiple injections: acceptability and safety. Geneva: World Health Organisation, 2014. http://www.who.int/ immunization/diseases/poliomyelitis/inactivated_polio_vaccine/ multiple_injections_acceptability_safety.pdf.

9. Wallace AS, Mantel C, Mayers G, et al. Experiences with provider and parental attitudes and practices regarding the administration of multiple injections during infant vaccination visits: lessons for vaccine introduction. Vaccine 2014;32:5301-10.

10. Smith PJ, Humiston SG, Marcuse EK, et al. Parental delay or refusal of vaccine doses, childhood vaccination coverage at 24 months of age, and the Health Belief Model. Public Health Rep 2011;126:135-46.

11. England PH. Immunisation against infectious diseases. chapter 8: vaccine safety and the management of advserse events following immunisation (Page 56: London: Public Health England, 2014. https://www.gov.uk/government/uploads/system/uploads/ attachment data/file/147868/Green-Book-Chapter-8-v4_0.pdf.

12. Purssell E. Parental fever phobia and its evolutionary correlates. $J$ Clin Nurs 2009;18:210-8.

13. Kai J. What worries parents when their preschool children are acutely ill, and why: a qualitative study. BMJ 1996;313:983-6.

14. Falagas ME, Zarkadoulia E. Factors associated with suboptimal compliance to vaccinations in children in developed countries: a systematic review. Curr Med Res Opin 2008;24:1719-41.

15. Brown KF, Kroll JS, Hudson MJ, et al. Factors underlying parental decisions about combination childhood vaccinations including MMR: a systematic review. Vaccine 2010;28:4235-48.

16. Tickner S, Leman PJ, Woodcock $A$. Factors underlying suboptimal childhood immunisation. Vaccine 2006;24:7030-6.

17. Samad L, Tate AR, Dezateux C, et al. Differences in risk factors for partial and no immunisation in the first year of life: prospective cohort study. BMJ 2006;332:1312-3.
18. Mills E, Jadad AR, Ross C, et al. Systematic review of qualitative studies exploring parental beliefs and attitudes toward childhood vaccination identifies common barriers to vaccination. $J$ Clin Epidemiol 2005;58:1081-8.

19. Larson HJ, Jarrett C, Eckersberger E, et al. Understanding vaccine hesitancy around vaccines and vaccination from a global perspective: a systematic review of published literature, 2007-2012. Vaccine 2014;32:2150-9.

20. Braun V, Clarke V. Using thematic analysis in psychology. Qual Res Psychol 2006;3:77-101.

21. Office for National Statistics. 2011 census analysis, local area analysis of qualifications across England and Wales 2014. London: OCNS. http://www.ons.gov.uk/ons/rel/census/2011-census-analysis/ local-area-analysis-of-qualifications-across-england-and-wales/ index.html.

22. Benin AL, Wisler-Scher DJ, Colson E, et al. Qualitative analysis of mothers' decision-making about vaccines for infants: the importance of trust. Pediatrics 2006;117:1532-41.

23. Larson HJ, Cooper LZ, Eskola J, et al. Addressing the vaccine confidence gap. Lancet 2011;378:526-35.

24. Vesikari T, Esposito S, Prymula R, et al. Immunogenicity and safety of an investigational multicomponent, recombinant, meningococcal serogroup $B$ vaccine $(4 \mathrm{CMen} B$ ) administered concomitantly with routine infant and child vaccinations: results of two randomised trials. Lancet 2013;381:825-35.

25. Leask J, Kinnersley P, Jackson C, et al. Communicating with parents about vaccination: a framework for health professionals. BMC Pediatr 2012;12:154.

26. Harrington PM, Woodman C, Shannon WF. Low immunisation uptake: is the process the problem? J Epidemiol Community Health 2000;54:394-400.

27. Le Ngoc Tho S, Ader F, Ferry T, et al. Vaccination against serogroup B Neisseria meningitidis: perceptions and attitudes of parents. Vaccine 2015;33:3463-70.

28. Bakhache P, Rodrigo C, Davie S, et al. Health care providers' and parents' attitudes toward administration of new infant vaccines--a multinational survey. Eur J Pediatr 2013;172:485-92.

29. Mameli C, Faccini M, Mazzali C, et al. Acceptability of meningococcal serogroup $B$ vaccine among parents and health care workers in Italy: a survey. Hum Vaccin Immunother 2014;10:3004-10.

30. Marshall $\mathrm{H}$, Clarke M, Sullivan T. Parental and community acceptance of the benefits and risks associated with meningococcal B vaccines. Vaccine 2014;32:338-44.

31. Public Health England. A 3 Minute Guide: protecting your baby against meningitis and septicaemia. secondary A 3 Minute Guide protecting your baby against meningitis and septicaemia : London Public Health England, 2015. accessed. https://www.gov.uk/government/uploads/system/uploads/ attachment_data/file/448028/9183_MenB-DL_3_Min_guide_17_web. pdf.

32. Public Health England. $A 3$ minute guide: protecting your baby against meningitis and septicaemia. secondary $A 3$ minute guide: protecting your baby against meningitis and septicaemia. London: Public Health England, 2015. https://www.gov.uk/government/ uploads/system/uploads/attachment_data/file/448054/9133_menB_ A5 Leaflet 17 web.pdf.

33. Public Health England. Using paracetamol to prevent and treat fever after MenB vaccination. London: Public Health England, 2015. https://www.gov.uk/government/uploads/system/uploads/ attachment_data/file/450890/9413-paracetamol-menB-2page-A405-web.pdf.

34. Public Health England. Meningococcal $B$ (MenB) vaccination programme. London: Public Health England, 2015. https://www.gov. uk/government/collections/meningococcal-b-menb-vaccinationprogramme.

35. Public Health England. Heath protection report. 10 (44), 16 December 2016. quarterly vaccination coverage statistics for children aged up to five years in the UK (COVER programme). London: Public Health England, 2016. https://www.gov.uk/government/uploads/ system/uploads/attachment_data/file/578705/hpr4416_cover_final_ v3_Web.pdf.

36. Public Health England. Routine childhood immunisations from summer 2016. London: Public Health England, 2016. https://www. gov.uk/government/uploads/system/uploads/attachment_data/file/ 533863/PHE 2016 Routine_Childhood_Immunisation_Schedule SUMMER2016.pdf.

37. Public Health England. preliminary vaccine coverage estimates for the meningococcal B (MenB) immunisation programme for England, update to the end of August 2016. London: Public Health England, 2016. https://www.gov.uk/government/uploads/system/uploads/ attachment_data/file/555057/hpr3216_menB.pdf. 